\title{
Rather Than Bash the VA, Let's Learn From Its Successes
}

Joan M. Cook, PhD

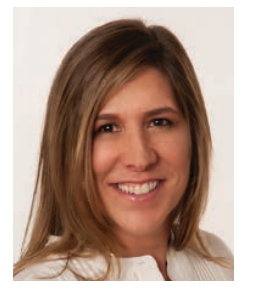

Joan Cook is an Associate Professor in the Department of Psychiatry at the Yale School of Medicine in New Haven, Connecticut.

Fed Pract. 2021;38(3):100-101. doi:10.12788/fp.0099
A new report by the Veterans Healthcare Policy Institute (VHPI) documents how elements included in many bills passed on Capitol Hill have failed to improve the efficacy of mental health services for our nation's former service members. ${ }^{1}$ The authors argue that while these efforts may be well intended, they often compound problems by squandering precious financial resources and stretching an already overtaxed workforce. Clearly, there are shortcomings in the US Department of Veterans Affairs (VA), our nation's largest integrated health care system, but rather than bash the VA, as the media and Congress tend to favor, let's learn from its successes as we improve its services.

To do this we must avoid several policy pitfalls. Consider, for example, the VA MISSION Act (38 USC \& 1703), which aimed to increase veteran access to quality health care outside the VA system. Studies confirmed that private sector mental health providers are not ready to deliver veteran-specific mental health care. ${ }^{2,3}$ Indeed, a RAND report found that psychotherapists in the private sector were unlikely to have the requisite skills necessary to deliver high-quality mental health care to service members or veterans. ${ }^{4}$

The MISSION Act meant to fix this clinical deficit by directing that competency standards be set for non-VA mental health providers who treat veterans for posttraumatic stress disorder (PTSD), traumatic brain injury, and military sexual trauma. But to date, no minimum competency standards have been set for nonVA mental health providers who treat veterans' common psychological conditions. A license is all they need.

Legislation like the MISSION Act and the newly passed Commander John Scott Hannon Act (38 USC \& 101) also assume that veterans who are suicidal or have mental health problems and don't go to the VA will seek care from private sector providers. Nothing is further from the truth. Many veterans are deeply re- sistant to seeking mental health care no matter where that care is delivered. ${ }^{4,5}$ Sometimes veterans believe that mental health problems are a sign of weakness and are loathe to seek help.

To address this issue, the VA pioneered models of integrated mental health and primary care services. ${ }^{6}$ This means that if a veteran goes to an outpatient primary care clinic at a VA medical facility or community-based outpatient clinic and discusses a mental health or substance abuse problem, the veteran can get immediate care with a mental health provider without making a separate mental health appointment. In addition, the VA already provides routine, annual screening for PTSD and sexual assault as well as depression and substance abuse at all its primary care clinics nationwide. Thanks to comprehensive screening (at a level unknown in most other health care systems) even if a veteran doesn't spontaneously report a trauma history or mental health distress, VA is able to identify the problem and offer help right in the primary care clinic. This one-stop shopping reduces the shame and stigma of having to make an appointment with a mental health provider, allows treatment to begin immediately, and reduces no shows at follow-up appointments.

Other health care systems are trying to copy the VA model of integrated primary and mental health care, but given our fragmented insurance system, it's not easy to replicate. ${ }^{7}$ According to Suzanne Gordon coauthor of the VHPI study, "This VA innovation encourages veterans, socialized by the military to conceal serious mental health problems, to get immediate help. So do many other VA programs, like peer support groups and networks. Legislation needs to strengthen, not weaken, such programs that are almost impossible to reproduce in the private sector." Outside of VA, mental health challenges faced by veterans likely go undetected, and many veterans will not receive the care that might change, or even save, their lives. 
VA best practices include an unprecedented national training initiative on 16 evidence-based psychotherapies that has been in operation for more than a decade. ${ }^{8}$ These high-quality treatments target debilitating conditions such as depression, PTSD, substance use disorders, insomnia, and chronic pain. ${ }^{9-13}$ More than 12,700 VA mental health providers have received training in these evidence-based psychotherapies.

"There is no way that non-VA health care systems can ever duplicate the quality of training and supervision that has now been provided, nationally, to VA mental health professionals," Josef Ruzek, PhD, former Director of the VA National Center for PTSD Dissemination and Training Division told me in a phone conversation (January 14, 2021). "Their program of training and implementation in the very best treatments for veteran mental health conditions stands as an international model of a complex, well-executed, large-scale program to improve mental health service delivery and improve the outcomes of treatment."

The VA not only paid for the training of these mental health providers, but also contributed substantial efforts to assist in the implementation and sustainability of such practices. These include policy changes mandating their availability at all VA facilities, designation of local evidence-based coordinators at each medical center, and even a nationwide PTSD mentoring program to help PTSD clinic managers make organizational changes and to guide the efforts of any VA clinician seeking advice on how to engage and work with a veteran living with PTSD. ${ }^{14}$ All these incredible dissemination and implementation endeavors have resulted in a substantial overall decrease in mental health symptoms and substance misuse behaviors and increase in functional outcomes, like improvement in relationship functioning and increase in quality of life for many veterans.

As a trauma psychologist and former VA employee, I urge lawmakers to assure that veterans are not sent to private sector providers who don't understand their unique needs and aren't trained to serve them well, and to similarly assure that systems of care are carefully designed to meet the specific needs of veterans.

\section{Author disclosures}

The author reports no actual or potential conflict of interest with regard to this article.

\section{Disclaimer}

The opinions expressed herein are those of the author and do not necessarily reflect those of Federal Practitioner, Frontline Medical Communications Inc., the US Government, or any of its agencies.

\section{References}

1. Gordon S, Lemle RB, Ruzek JI, Kudler H. Creating effective solutions, programs, and policies to improve veterans' mental health care. Published January 2021. Accessed February 22, 2021. https://static1.squarespace.com /static/5b19e25e89c1722037f0fdab/t/6018731daf20e7024b 5d6aa8/1612215071469/VHPI_MHReport.pdf

2. Tanielian T, Farris C, Batka C, et al. Ready to serve: community-based provider capacity to deliver culturally competent, quality mental health care to veterans and their families. Published 2014. Accessed February 22, 2021. https://www rand.org/pubs/research reports/RR806.html

3. Tanielian T, Farmer CM, Burns RM, et al, Ready or not? Assessing the capacity of New York State health care providers to meet the needs of veterans. Published 2018. Accessed February 22, 2021. https://www.rand.org/pubs /research_reports/RR2298.html.

4. Crawford EF, Elbogen EB, Wagner HR, Kudler $\mathrm{H}$, Calhoun PS, Brancu M, Straits-Troster KA. Surveying treatment preferences in U.S. Iraq-Afghanistan Veterans with PTSD symptoms: a step toward veteran-centered care. J Trauma Stress. 2015 Apr;28(2):118-26. doi: 10.1002/jts.21993.

5. Hoge CW, Castro CA, Messer SC, et al. Combat duty in Iraq and Afghanistan, mental health problems, and barriers to care. New England Journal of Medicine 351:13-22, 2004

6. Zeiss AM, Karlin BE. Integrating mental health and primary care services in the Department of Veterans Affairs Health Care System. J Clin Psychol Med Settings. 2008;15(1):7378. doi:10.1007/s10880-008-9100-4

7. Gordon S. Wounds of War: How the VA Delivers Health, Healing and Hope to the Nation's Veterans. Cornell University Press; 2018.

8. Karlin BE, Cross G. From the laboratory to the therapy room: national dissemination and implementation of evidence-based psychotherapies in the U.S. Department of Veterans Affairs Health Care System. Am Psychol. 2014:69(1):19-33. doi:10.1037/a0033888

9. Stewart MO, Raffa SD, Steele JL, et al. National dissemination of interpersonal psychotherapy for depression in veterans: therapist and patient-level outcomes. J Consult Clin Psychol. 2014;82(6):1201-1206. doi:10.1037/a0037410

10. Karlin BE, Ruzek JI, Chard KM, et al. Dissemination of evidence-based psychological treatments for posttraumatic stress disorder in the Veterans Health Administration. $J$ Trauma Stress. 2010;23(6):663-673. doi:10.1002/jts.20588

11. DeMarce JM, Gnys M, Raffa SD, Kumpula M, Karlin BE. Dissemination of cognitive behavioral therapy for substance use disorders in the Department of Veterans Affairs Health Care System: description and evaluation of veteran outcomes [published online ahead of print, 2019 Oct 23]. Subst Abus. 2019;1-7. doi:10.1080/08897077.2019.1674238

12. Karlin BE, Trockel M, Spira AP, Taylor CB, Manber R. National evaluation of the effectiveness of cognitive behavioral therapy for insomnia among older versus younger veterans. Int J Geriatr Psychiatry. 2015;30(3):308-315. doi:10.1002/gps.4143

13. Stewart MO, Karlin BE, Murphy JL, et al. National dissemination of cognitive-behavioral therapy for chronic pain in veterans: therapist and patient-level outcomes. Clin J Pain. 2015;31(8):722-729. doi:10.1097/AJP.0000000000000151

14. Bernardy NC, Hamblen JL, Friedman MJ, Ruzek JI, McFall ME. Implementation of a posttraumatic stress disorder mentoring program to improve treatment services. Psycholog Trauma. 2011;3(3):292-299. doi:10.1037/a0024847 